ГРИГОРЬЕВА Ксения Сергеевна - кандидат социологических наук, научный сотрудник Института социологии Федерального научно-исследовательского социологического центра РАН (117218, Россия, г. Москва, ул. Кржижановского, 24/35, корп. 5; kseniagrigoryeva@yandex.ru)

\title{
СТОЛКНОВЕНИЕ ЦИВИЛИЗАЦИЙ В БАШКОРТОСТАНЕ? ЭМПИРИЧЕСКАЯ ПРОВЕРКА ТЕЗИСОВ С. ХАНТИНГТОНА
}

\begin{abstract}
Аннотация. В статье на материалах эмпирического исследования, проведенного в Республике Башкортостан, проверяется теория столкновения цивилизаций С. Хантингтона. Результаты и исследования опровергают тезис о несовместимости ценностей мусульманской и православно-славянской цивилизаций. Напротив, представители двух цивилизаций проявили солидарность в вопросах значимости свободы, справедливости, верховенства закона, допустимости влияния религиозных организаций на принятие политических решений (статистическая значимость различий между группами не обнаружена). Автор анализирует тезис С. Хантингтона о распространении религиозного радикализма, особенно среди молодежи, лиц с высоким уровнем образования, представителей среднего класса. На основе данных об отношении местного населения к приезжим разной цивилизационной принадлежности проверяется тезис о сплочении цивилизаций.
\end{abstract}

Ключевые слова: столкновение цивилизаций, Башкортостан, православные, мусульмане, политические ориентации, ценности, религиозный радикализм

$\mathrm{B}$ своей знаменитой теории столкновения цивилизаций С. Хантингтон выдвинул утверждение, что в ближайшем будущем «границы, разделяющие человечество, и преобладающие источники конфликтов будут определяться культурой» [Хантингтон 1994: 33], а не идеологией и экономикой. Причем ключевую роль в конфронтации культур сыграет религия.

Именно религия, согласно С. Хантингтону, более, чем что-либо иное, разделяет людей. Даже этничность не возводит столь труднопреодолимую границу, поскольку «можно быть полуфранцузом и полуарабом и даже гражданином обеих этих стран. Куда сложнее быть полукатоликом и полумусульманином» [Хантингтон 1994: 37].

Религиозные различия, по С. Хантингтону, влекут за собой разногласия по широкому кругу политических вопросов, в т.ч. взаимодействия граждан и государства, значимости политических свобод, прав человека.

В соответствии с теорией столкновения цивилизаций конфликт происходит на двух уровнях. На макроуровне он разворачивается между странами, принадлежащими к разным цивилизациям (западной, исламской, конфуцианской и др.), тогда как микроуровень представлен столкновением групп, проживающих в границах одного национального государства.

\section{Критика теории столкновения цивилизаций}

Теория С. Хантингтона неоднократно подвергалась критике, причем критиковались как ее содержательные аспекты, так и допущенные автором методологические неточности.

Одним из первых критические соображения высказал Ф. Аджами, указав, что С. Хантингтон переоценивает значение традиционализма и религиозного фундаментализма и недооценивает роль национальных государств [Ajami 1993].

Дж. Киркпатрик отмечал, что предложенный С. Хантингтоном перечень цивилизаций является неубедительным. Кроме того, он упускает из виду, что внутрицивилизационные конфликты могут быть не менее острыми и взрыво- 
опасными, чем межцивилизационные [Kirkpatrick 1993]. Аналогичные замечания высказывал и Дж. Курт [Kurth 1994].

Р. Маркс писал о том, что теория С. Хантингтона несостоятельна с точки зрения используемой методологии и является не более чем претенциозной политической спекуляцией [Marks 2000]. Э. Саид усматривал в теории столкновения цивилизаций непозволительное упрощение и попытку навешивания «неадекватных ярлыков» на исламский мир [Said 2001].

Теорию С. Хантингтона неоднократно пытались проверить эмпирическим путем. Как правило, исследования были нацелены на то, чтобы подтвердить или опровергнуть тезис о распространенности вооруженных конфликтов между странами, принадлежащими к разным цивилизациям. Полученные результаты в абсолютном большинстве случаев показывали его ошибочность.

К примеру, Б. Рассет, Дж. Онил и М. Кокс, предпринявшие исследование межгосударственных конфликтов за период с 1950 по 1992 гг., пришли к выводу, что теория столкновения цивилизаций мало что объясняет. При прочих равных условиях вооруженный конфликт между государствами, принадлежащими к разным цивилизациям, не более вероятен, чем военное столкновение культурно близких стран [Russett, Oneal, Cox 2000].

Попытки эмпирической проверки теории столкновения цивилизаций на микроуровне встречаются несколько реже. Одной из наиболее интересных работ в этом ряду является статья Дж. Фокса «Этнические меньшинства и столкновение цивилизаций: количественный анализ тезисов Хантингтона» [Fox 2002], где исследуются данные проекта Minorities at Risk (MAR3), включающие информацию о 275 политически активных этнических меньшинствах в разных странах мира. Результаты исследования свидетельствуют о том, что межцивилизационные конфликты составляют небольшую долю всех межэтнических столкновений, происходящих внутри государств. Кроме того, конфликты между западной, конфуцианской и исламской цивилизацией, которые, по мнению С. Хантингтона, должны преобладать в мире, в действительности представляют лишь малую часть общего числа тех столкновений, которые можно отнести к межцивилизационным. Наконец, тезис о том, что интенсивность конфликтов между группами, принадлежащими к разным цивилизациям, возрастет после окончания «холодной войны», также не подтверждается.

В российском научном сообществе теория столкновения цивилизаций также широко обсуждалась. Одна из первых научных дискуссий на эту тему состоялась на страницах журнала «Полис» в 1995 г. [Пантин и др. 1995]. Одновременно российские исследователи, как и их западные коллеги, стали предпринимать попытки эмпирической проверки тезисов о столкновении цивилизаций.

Так, во второй половине 1990-х гг. научная группа под руководством Л.М. Дробижевой проводила исследования в Республике Татарстан, в ходе которых проверялась гипотеза о том, что принадлежность к разным цивилизациям с необходимостью влечет за собой труднопреодолимые различия в политических ориентациях, нормативных представлениях. Полученные результаты показали, что русские и татары, которые в соответствии с классификацией С. Хантингтона могут быть отнесены к православно-славянской и исламской цивилизации соответственно, демонстрируют высокое сходство политических представлений и общность ценностных ориентаций. Впоследствии эти выводы подтвердились на материалах научно-исследовательских проектов, реализованных в первой половине нулевых годов в других российских регионах [Дробижева 2003].

Несмотря на неоднократное эмпирическое опровержение теории столкновения цивилизаций, она до сих пор не утратила своей популярности. Нередко приводится аргумент, согласно которому проверка тезисов С. Хантингтона на 
основе анализа данных, полученных в 1990-е гг. (а именно на этот период приходится большинство подобных эмпирических исследований), недостаточно корректна. Одна из основных идей политолога состояла в том, что межцивилизационные конфликты станут доминировать в будущем, спустя определенное время после окончания «холодной войны», а значит, исследования, проведенные сразу после ее завершения, не смогут уловить предсказанные изменения. Сегодня, по прошествии 25 лет после распада СССР и завершения «холодной войны», подобные доводы уже не работают: прогнозы С. Хантингтона, если они верны, с необходимостью должны находить отражение в реальности.

Ниже мы попытаемся проверить теорию столкновения цивилизаций на материалах эмпирического исследования, проведенного в 2017 г. в Республике Башкортостан.

\section{Республика Башкортостан: регион, где проходят линии}

\section{межцивилизационного разлома?}

Будучи регионом со сложным этноконфессиональным составом, Башкортостан вполне отвечает описанию территории, по которой проходят линии межцивилизационного разлома. Здесь соприкасаются тюркские и славянские народы, между которыми, как подчеркивает С. Хантингтон, исторически велась борьба [Хантингтон 1994: 40].

Используя категоризацию, предложенную С. Хантингтоном, мы будем относить татар и башкир, исповедующих ислам, к исламской цивилизации, русских, исповедующих православие, - к православно-славянской.

Нашей исходной гипотезой станет предположение, что представители данных цивилизаций по-разному смотрят на отношения между человеком и государством, государством и религиозными учреждениями; в разной степени привержены ценностям свободы, равенства и верховенства закона. Кроме того, будет протестировано утверждение С. Хантингтона, что распространение приобретает поддержка религиозного радикализма, особенно среди молодежи, лиц с высоким уровнем образования и представителей среднего класса. Наконец, мы проверим тезис о «сплочении цивилизаций» (синдроме «братских групп»), используя данные об отношении местного населения к приезжим, принадлежащим к разным цивилизациям.

\section{Эмпирическая база и инструментарий исследования}

Эмпирическую базу исследования составляют материалы массового опроса, проведенного в Республике Башкортостан в июле 2017 г. по квотной районированной выборке, репрезентирующей население РБ. В выборку были включены 14 городов и 15 сельских районов, представляющих 6 геоэкономических зон республики: центральную, западную, южную, северо-западную, северо-восточную и уральскую. Были заложены квоты по полу, возрасту, образованию и национальности (башкиры, татары, русские). Всего были опрошены 1035 респондентов. Ошибка выборки составляет $\pm 3 \%$.

\section{Политические и ценностные ориентации представителей исламской и православно-славянской цивилизаций}

Результаты проведенного исследования опровергают гипотезу о фундаментальных различиях в политических ориентациях представителей исламской и православно-славянской цивилизации. Напротив, последние проявляют полную солидарность в вопросах о том, какие общие цели могли бы объединить российское общество, следует ли гражданину ориентироваться на собственные силы или ждать помощи от государства, должны ли Русская православная 
церковь и Духовное управление мусульман влиять на принятие политических решений.

Так, ключевыми целями, способными объединить российское общество, представители обеих групп считают обеспечение закона и порядка в стране, благосостояния народа и справедливости в обществе (см. табл. 1).

Таблица 1

Цели, способные объединить российское общество, \%

\begin{tabular}{|l|c|c|}
\hline \multicolumn{1}{|c|}{ Варианты ответов } & $\begin{array}{c}\text { Представители } \\
\text { исламской } \\
\text { цивилизации }\end{array}$ & $\begin{array}{c}\text { Представители } \\
\text { православно- } \\
\text { славянской } \\
\text { цивилизации }\end{array}$ \\
\hline Укрепление единства страны & 31,5 & 33,0 \\
\hline Обеспечение закона и порядка в стране & 51,6 & 47,9 \\
\hline $\begin{array}{l}\text { Предотвращение войн, эпидемий, экологических } \\
\text { катастроф }\end{array}$ & 32,5 & 33,0 \\
\hline Возрождение России как великой державы & 30,4 & 28,1 \\
\hline Укрепление обороноспособности страны & 21,6 & 29,2 \\
\hline Обеспечение справедливости в обществе & 38,3 & 37,5 \\
\hline Обеспечение благосостояния народа & 52,4 & 46,2 \\
\hline Другие цели & 0,3 & 0,3 \\
\hline Затрудняюсь ответить & 2,8 & 1,7 \\
\hline
\end{tabular}

Это свидетельствует о том, что, вопреки утверждению С. Хантингтона, ценности верховенства закона, равенства и справедливости разделяются не только представителями западной цивилизации, но и представителями исламской и православно-славянской цивилизаций и не являются источником противоречий.

Респонденты из обеих групп демонстрируют единодушие и по вопросу о взаимоотношениях гражданина и государства (см. табл. 2).

Таблица 2

Представления о взаимоотношениях гражданина и государства, \%

\begin{tabular}{|l|c|c|}
\hline \multicolumn{1}{|c|}{ Варианты ответов } & $\begin{array}{c}\text { Представители } \\
\text { исламской } \\
\text { цивилизации }\end{array}$ & $\begin{array}{c}\text { Представители } \\
\text { православно- } \\
\text { славянской } \\
\text { цивилизации }\end{array}$ \\
\hline $\begin{array}{l}\text { Согласны / скорее согласны с тем, что человек } \\
\text { должен сам обеспечивать себя и свою семью, а не } \\
\text { рассчитывать на поддержку со стороны государства }\end{array}$ & 31,7 & 31,7 \\
\hline $\begin{array}{l}\text { Согласны / скорее согласны с тем, что государство } \\
\text { должно обеспечивать средний уровень } \\
\text { благосостояния для своих граждан }\end{array}$ & 67,4 & 67,3 \\
\hline Затруднились ответить & 0,9 & 1,0 \\
\hline
\end{tabular}

Как видно из приведенных данных, подавляющее большинство опрошенных полагают, что государство должно заботиться о благополучии своих граждан.

Вопрос о допустимости влияния религиозных учреждений (РПЦ и ДУМ) на принятие государственных решений тоже не является предметом разногласий между представителями исламской и православно-славянской цивилизации. Примерно равные доли респондентов из обеих групп считают, что религиозные учреждения (не) должны оказывать влияние на политические решения. Причем полученные результаты свидетельствуют о том, что ни православные, ни мусульмане не склонны проявлять фаворитизм в отношении «своих» религиозных организаций (см. табл. 3). 
Таблица 3

Оценка респондентами допустимости влияния религиозных организаций на принятие государственных решений, \%

\begin{tabular}{|l|c|c|c|c|}
\hline \multirow{2}{*}{} & \multicolumn{2}{|c|}{$\begin{array}{c}\text { Представители исламской } \\
\text { цивилизации }\end{array}$} & \multicolumn{2}{|c|}{$\begin{array}{c}\text { Представители } \\
\text { православно-славянской } \\
\text { цивилизации }\end{array}$} \\
\cline { 2 - 5 } & $\begin{array}{c}\text { «Да», } \\
\text { «скорее да» }\end{array}$ & $\begin{array}{c}\text { «нетет, } \\
\text { «сорее нет» }\end{array}$ & $\begin{array}{c}\text { «Да», } \\
\text { «скорее да» }\end{array}$ & $\begin{array}{c}\text { «Нет», } \\
\text { «скорее нет» }\end{array}$ \\
\hline $\begin{array}{l}\text { Должны ли Духовные управления } \\
\text { мусульман оказывать влияние на } \\
\text { принятие государственных решений? }\end{array}$ & 40,7 & 47,0 & 38,0 & 46,8 \\
\hline $\begin{array}{l}\text { Должна ли Русская православная } \\
\text { церковь оказывать влияние на } \\
\text { принятие государственных решений? }\end{array}$ & 40,0 & 47,2 & 44,1 & 43,4 \\
\hline
\end{tabular}

В ценностных ориентациях представители двух цивилизаций также демонстрируют не различия, а сходство (см. табл. 4).

Таблица 4

Распределение ответов на вопрос: «Люди по-разному понимают, что такое "хорошо жить", быть счастливым. Выберите из списка на карточке не более трех ответов то, что Вы для себя считаете самым важным», \%

\begin{tabular}{|l|c|c|}
\hline \multicolumn{1}{|c|}{ Варианты ответов } & $\begin{array}{c}\text { Представители исламской } \\
\text { цивилизации }\end{array}$ & $\begin{array}{c}\text { Представители } \\
\text { православно-славянской } \\
\text { цивилизации }\end{array}$ \\
\hline Пользоваться уважением людей & 36,3 & 39,7 \\
\hline Иметь хорошую, интересную работу & 50,4 & 50,7 \\
\hline Иметь хорошую семью & 74,3 & 69,9 \\
\hline $\begin{array}{l}\text { Чувствовать себя свободным } \\
\text { человеком }\end{array}$ & 23,7 & 25,2 \\
\hline Жить обеспеченно, в достатке & 69,3 & 63,4 \\
\hline Другое & 2,6 & 3,8 \\
\hline Затрудняюсь ответить & 0,9 & 1,0 \\
\hline
\end{tabular}

Как видно из табл. 4, респонденты из обеих групп самым важным считают иметь хорошую семью; жить обеспеченно, в достатке; иметь интересную работу.

\section{Поддержка религиозного радикализма}

Было бы немалым преувеличением говорить о поддержке религиозного радикализма как представителями исламской, так и представителями православнославянской цивилизации.

Позитивно оценивают деятельность тех, кто готов защищать чистоту религиозной веры с оружием в руках, лишь 3,3\% мусульман и 6,7\% православных. Причем, вопреки утверждению С. Хантингтона, доля молодежи, придерживающейся такой позиции, не превышает аналогичной доли в старших возрастных когортах (см. табл. 5).

Уровень образования также не оказывает значимого влияния на одобрение деятельности религиозных радикалов. Заявление о том, что их поддерживают высокообразованные люди, не находит эмпирического подтверждения (см. табл. 6).

Не влияет на поддержку религиозного радикализма и материальное положение респондентов. Представители среднего класса высказывают одобрение в отношении тех, кто готов защищать чистоту веры с оружием в руках, не чаще представителей низшего и высшего классов (5,1\% против $4,7 \%$ и $5,7 \%$ соответственно). 
Таблица 5

Отношение к тем, кто готов с оружием в руках защищать чистоту своей религиозной веры, среди респондентов разного возраста, \%

\begin{tabular}{|l|c|c|c|c|c|}
\hline \multirow{2}{*}{ Варианты ответов } & \multicolumn{5}{|c|}{ Возрастные группы, лет } \\
\cline { 2 - 6 } & до 30 & $\mathbf{3 1 - 4 0}$ & $\mathbf{4 1 - 5 0}$ & $\mathbf{5 1 - 6 0}$ & от 61 \\
\hline $\begin{array}{l}\text { Это настоящие герои, которые } \\
\text { заслуживают уважения }\end{array}$ & 5,0 & 4,4 & 4,9 & 7,0 & 5,2 \\
\hline $\begin{array}{l}\text { Эти люди заблуждаются, но их в } \\
\text { чем-то можно понять }\end{array}$ & 29,2 & 29,6 & 27,2 & 19,3 & 26,5 \\
\hline $\begin{array}{l}\text { Это преступники, с которыми } \\
\text { следует бороться }\end{array}$ & 41,6 & 40,8 & 49,5 & 51,3 & 47,1 \\
\hline Затрудняюсь ответить & 24,2 & 25,2 & 18,5 & 22,5 & 21,3 \\
\hline
\end{tabular}

Таблица 6

Отношение к тем, кто готов с оружием в руках защищать чистоту своей религиозной веры, среди респондентов с разным уровнем образования, \%

\begin{tabular}{|l|c|c|c|}
\hline \multirow{2}{*}{\multicolumn{1}{|c|}{ Варианты ответов }} & \multicolumn{3}{|c|}{ Уровень образования } \\
\cline { 2 - 4 } & $\begin{array}{c}\text { полное и неполное } \\
\text { среднее }\end{array}$ & $\begin{array}{c}\text { среднее } \\
\text { специальное }\end{array}$ & $\begin{array}{c}\text { высшее и } \\
\text { неоконченное } \\
\text { высшее }\end{array}$ \\
\hline $\begin{array}{l}\text { Это настоящие герои, которые } \\
\text { заслуживают уважения }\end{array}$ & 8,8 & 3,3 & 5,9 \\
\hline $\begin{array}{l}\text { Эти люди заблуждаются, но их в } \\
\text { чем-то можно понять }\end{array}$ & 22,1 & 27,6 & 28,1 \\
\hline $\begin{array}{l}\text { Это преступники, с которыми } \\
\text { следует бороться }\end{array}$ & 40,9 & 43,6 & 51,0 \\
\hline Затрудняюсь ответить & 28,2 & 25,4 & 15,0 \\
\hline
\end{tabular}

\section{«Сплочение цивилизаций»}

Полученные данные не подтвердили и тезис о «сплочении цивилизаций», согласно которому жители других стран и регионов воспринимаются как «свои», если принадлежат к той же цивилизации.

Как показало наше исследование, жители Башкортостана (как мусульмане,

Поддержка ограничительных мер в отношении приезжих из других регионов России, \%

\begin{tabular}{|l|c|c|c|c|}
\hline & \multicolumn{2}{|c|}{$\begin{array}{c}\text { Представители } \\
\text { исламской цивилизации }\end{array}$} & \multicolumn{2}{|c|}{$\begin{array}{c}\text { Представители } \\
\text { православно- } \\
\text { славянской } \\
\text { цивилизации }\end{array}$} \\
\cline { 2 - 5 } & $\begin{array}{c}\text { «За», } \\
\text { «скорее за» }\end{array}$ & $\begin{array}{c}\text { «ротив», } \\
\text { «скореe } \\
\text { против» }\end{array}$ & $\begin{array}{c}\text { «За», } \\
\text { «скорее за» }\end{array}$ & $\begin{array}{c}\text { «Против», } \\
\text { «скореe } \\
\text { против» }\end{array}$ \\
\hline $\begin{array}{l}\text { Ограничение приезда в Башкортостан } \\
\text { на постоянное жительство и на заработки } \\
\text { приезжих из других регионов }\end{array}$ & 49,5 & 40,7 & 50,5 & 39,1 \\
\hline $\begin{array}{l}\text { Ограничение приезда в Башкортостан } \\
\text { на постоянное жительство и на заработки } \\
\text { приезжих мусульман }\end{array}$ & 49,1 & 39,3 & 56,4 & 33,6 \\
\hline $\begin{array}{l}\text { Ограничение приезда в Башкортостан } \\
\text { на постоянное жительство и на заработки } \\
\text { приезжих православных }\end{array}$ & 49,0 & 39,8 & 55,9 & 34,0 \\
\hline
\end{tabular}


так и православные) примерно одинаково относятся ко всем приезжим, вне зависимости от их «Цивилизационной» принадлежности (см. табл. 7).

Как видно из приведенных данных, около половины всех опрошенных (как мусульман, так и православных) поддерживают ограничительные меры в отношении приезжих, причем, когда речь идет о «цивилизационно близких» приезжих, уровень поддержки указанных мер остается на том же уровне или даже незначительно возрастает.

\section{Выводы}

Исследование, проведенное в 2017 г. в Республике Башкортостан, в очередной раз не дало эмпирического подтверждения теории столкновения цивилизаций С. Хантингтона.

Полученные данные опровергли тезис о несовместимости политических и ценностных ориентаций представителей исламской и православно-славянской цивилизаций. Напротив, в вопросах значимости свободы, справедливости, верховенства закона, допустимости влияния религиозных организаций на принятие политических решений они проявили единодушие (статистически значимых различий между группами не обнаружено).

Не нашло подтверждения и утверждение о распространении поддержки религиозного радикализма, особенно среди молодежи, лиц с высоким уровнем образования, представителей среднего класса.

Не подтвердилось и положение о «сплочении цивилизаций». Результаты исследования продемонстрировали полное отсутствие фаворитизма как со стороны мусульман, так и со стороны православных по отношению к «цивилизационно близким» приезжим из других регионов РФ.

Статья подготовлена при поддержке Российского научного фонда, грант №14-18-01963-П.

\section{Список литературы}

Дробижева Л.М. 2003. Социальные проблемы межнациональных отношений в постсоветской России. М.: Центр общечеловеческих ценностей. 376 с.

Пантин И.К., Хорос В.Г., Кара-Мурза А.А., Панарин А.С., Рашковский Е.Б., Цымбурский В.Л., Умов В.И., Ильин М.В. 1995. Цивилизационная модель международных отношений и ее импликации (научная дискуссия в редакции «Полиса»). - Полис. Политические исследования. № 1. С. 121-165.

Хантингтон С. 1994. Столкновение цивилизаций? - Полис. Политические исследования. № 1. С. 33-48.

Ajami F. 1993. The Summoning. - Foreign Affairs. Vol. 72. №. 4. P. 2-9.

Fox J. 2002. Ethnic Minorities and the Clash of Civilizations: A Quantitative Analysis of Huntington's Thesis. - British Journal of Political Science. Vol. 32. No. 3. P. 415-434.

Kirkpatrick J.J. 1993. The Modernizing Imperative: Tradition and Change. - Foreign Affairs. Vol. 72. No. 4. P. 22-24.

Kurth J. 1994. The Real Clash. - The National Interest. № 37. P. 3-15.

Marks R. 2000. The Clash of Civilizations and the Remaking of World Order (review). - Journal of World History. № 11(1). P. 101-104.

Russett B.M., Oneal J.R., Cox M. 2000. Clash of Civilizations, or Realism and Liberalism Déjà Vu? Some Evidence. - Journal of Peace Research. Vol. 37. No. 5. P. 583-608.

Said E.W. 2001. The Clash of Ignorance. - The Nation. Vol. 273. No. 12. P. 11-14. 
GRIGOR'EVA Kseniya Sergeevna, Cand.Sci. (Soc.), Researcher of the Sociological Institute - branch of the Federal Center of Theoretical and Applied Sociology, Russian Academy of Sciences (bld. 5, 24/35 Krzhizhanovskogo St, Moscow, Russia, 117218; kseniagrigoryeva@yandex.ru)

\title{
THE CLASH OF CIVILIZATIONS IN BASHKORTOSTAN? AN EMPIRICAL TEST OF S. HUNTINGTON'S THESIS
}

\begin{abstract}
On the materials of the empirical research conducted in the Republic of Bashkortostan, the article checks $S$. Huntington's theory of the clash of civilizations. The the results of the study materials refute the thesis of a theory of Muslim and Orthodox-Slavish civilizations' political and value assumptions incompatibility. On the contrary, representatives of both civilizations have manifested solidarity in issues of significance of freedom, justice, primacy of law and about permissibility of religious organizations' impact on political decision-making (no statistically significant difference between groups has been found). S. Huntington's claim on expansion of religious radicalism support also found no vindication. Contrary to S. Huntington's allegations, share of youth who adhere to this position does not exceed the similar share of older people. Based on the data on the attitude of the local population to visitors of different civilizational affiliation, the thesis about the rallying of civilizations is checked. About a half of all respondents supports restrictive measures in regard of newcomers, irrespective of their civilizational belonging.
\end{abstract}

Keywords: clash of civilizations, Bashkortostan, Orthodox, Muslims, political orientations, values, religious radicalism

МАКАРЕНКО Екатерина Игоревна - кандидат исторических наук, доцент кафедры социологии и управления Московского автомобильно-дорожного государственного технического университета (МАДИ) (125319, Россия, г. Москва, Ленинградский пр-кm, 64; Makarenko_madi@mail.ru)

\section{СОЦИАЛЬНО-ИСТОРИЧЕСКИЕ ОСОБЕННОСТИ ВОСПРОИЗВОДСТВА ТЕХНИЧЕСКОЙ ИНТЕЛЛИГЕНЦИИ}

\begin{abstract}
Аннотация. В статье рассматриваются социально-исторические особенности воспроизводства отечественной технической интеллигенции на разных этапах ее деятельности: дореволюционном (18611917 гг.), советском (1917-1991 гг.) и постсоветском (с 1991 г. по настоящее время). Анализ современных характерных черт воспроизводства технической интеллигенции представлен на основе социологического полустандартизированного интервью со студентами технического вуза, проведенного весной 2018 r.
\end{abstract}

Ключевые слова: техническая интеллигенция, воспроизводство, инженерные кадры, профессиональное образование, профориентация, трудоустройство

B настоящее время в нашей стране происходят кардинальные изменения в области проведения экономической и промышленной политики, связанные, прежде всего, с переходом к новым цифровым технологиям в глобальном масштабе. Поэтому вопросы определения приоритетов научно-технологического развития, его квалифицированного кадрового обеспечения приобретают ключевое значение не только для дальнейшего развития отечественной экономики и производства, но и для национальной безопасности в целом. Социальной и кадровой базой инновационного прорыва экономики страны может и должна стать техническая интеллигенция - слой, который имеет в России давнюю историю, связанную, прежде всего, с развитием профессионального технического образования. К технической интеллигенции автор 